Published in final edited form as:

Clin Geriatr Med. 2016 May ; 32(2): 215-226. doi:10.1016/j.cger.2016.01.013.

\title{
Epidemiology of Multimorbidity in Older Adults with Cardiovascular Disease
}

\author{
Susan P. Bell, MBBS, MSCI ${ }^{1,2}$ and Avantika A. Saraf, MPH ${ }^{1,2}$ \\ ${ }^{1}$ Division of Cardiovascular Medicine, Department of Medicine, Vanderbilt University Medicine \\ Center \\ ${ }^{2}$ Center for Quality Aging, Division of Geriatric Medicine, Vanderbilt University Medical Center
}

\author{
Keywords \\ Older adults; Multimorbidity; Cardiovascular disease
}

\section{Introduction}

The proportion of adults aged 65 and over is rapidly increasing and will comprise approximately $19 \%$ of the US population by the year 2030 including 19 million adults over the age of $85 .{ }^{1}$ The result of this remarkable demographic shift imposes significant implications for overall future health care management where age is a driving factor in a multitude of disease processes, including cardiovascular disease (CVD), and contributes the most substantial risk. In 2013, CVD was responsible for over 17 million deaths globally, an increase of 5 million (40\%) annually since 1990, despite increasing advances in cardiovascular treatments and health care delivery. ${ }^{2}$ The overwhelming driver of this increase can be attributed to population aging (55\%) and to a lesser extent population growth (25\%). In the US, CVD affects approximately 40 million individuals over the age of 65 and remains the leading cause of morbidity and mortality. 3,4

The increasing prevalence of co-existing disease processes in this aging population further adds to the complexity and challenges facing patients with CVD and the providers that care for them. The diagnosis and management of CVD in older adults requires an in-depth understanding of the interplay between patient heterogeneity, the accumulation and activity of chronic and acute conditions, functional status, pharmacology, and social factors. However, the utilization of single disease practice guidelines continues to remain the standard of care across health care settings irrespective of age and presence of multiple coexisting chronic conditions. ${ }^{5,6}$ In fact, the most common chronic co-existing condition in older adults is the presence of multimorbidity, the coexistence of 2 or more chronic conditions. ${ }^{7}$ The concept of multimorbidity differs from the familiar framework of comorbidity in that at any one time several conditions may be equally important and overlapping in management strategies and require comparable intensity and simultaneous

Susan P. Bell, Division of Cardiovascular Medicine, Center for Quality Aging, Address: 2525 West End Avenue, Suite 350, Nashville TN - 37203, Phone: (615)-322-6370; Fax: (615)-936-1754, susan.p.bell@ vanderbilt.edu. 
management strategies to achieve optimal patient-centered outcomes and quality of life. This chapter will examine the epidemiological relationships and importance of multimorbidity in older adults with CVD.

\section{Prevalence of Multimorbidity}

Multimorbidity rapidly increases with age such that it is prevalent in over $70 \%$ of individuals 75 years or older. ${ }^{8}$ The accumulation of chronic conditions as a result of genetics, lifestyle choices, environmental factors, treatment of prior conditions (e.g. heart failure as an adverse consequence of chemotherapy regimens) and aging itself culminates in a vastly heterogenic older population of adults that require balancing the management of multiple medical problems. By the age of 65 years over $60 \%$ of adults will have 2 or more chronic conditions, $>25 \%$ will have 4 or more chronic conditions and almost $10 \%$ will have 6 or more (Figure 1). ${ }^{8}$ These rates increase by each decade and result in $>50 \%$ over individuals 85 years and older suffering from 4 or more chronic conditions and $25 \%$ with 6 or more chronic conditions. ${ }^{8}$ The prevalence is high across all racial and ethnic groups, however, the pattern of multimorbidity by race changes over the age spectrum. ${ }^{9}$ Through ages 50-59 years, multimorbidity is more common in Blacks as compared to Whites, and is higher in Whites as compared to Asians. Furthermore, the presence of significant multimorbidity ( 5 or more conditions) through ages 50-59 is higher in Blacks as compared to Whites and Asians. In adults 60 and older, the relationship of 5 or more conditions appears to change with multimorbidity being more common in Whites as compared to Blacks and Asians. ${ }^{9}$

Multimorbidity is extremely common and rapidly increases in a similar pattern with age in both men and women. Figure 2 demonstrates the patterns of increasing numbers of chronic conditions ( $\geq 2$ conditions, $\geq 4$ conditions, $\geq 6$ conditions) in men and women below 65 years of age and 65 years and older. ${ }^{8}$ In one study, among community dwelling individuals, the prevalence of 5 or more conditions is more common in men over the age of 60 as compared to women ${ }^{9}$ but this finding is not consistent with other reported data that has demonstrated in Medicare Beneficiaries (Fee-for-service claims) the prevalence of multimorbidity is slightly higher in women compared to men. ${ }^{8,9}$ In addition, the combinations of chronic diseases are different in men and women with men more likely to have the presence of cancer, CVD and cardiovascular risk factors (HTN, DM, hyperlipidemia) as compared to women that had a higher prevalence of arthritis and depression. ${ }^{10}$

\section{Multimorbidity and Geriatric Syndromes}

Evaluation of the impact of multimorbidity should not only include the contributing effects of chronic co-existing diagnoses but also the prevalence of common and frequently underreported geriatric syndromes. Geriatric syndromes represent a group of clinical conditions involving multiple organ systems and that sometimes share common causative factors. ${ }^{11,12}$ These include a number of conditions which unlike traditional syndromes do not fit a discrete metabolic, pathological or genetic disease category. Examples of which include falls, cognitive impairment, delirium, weight loss, anorexia, pressure ulcers, functional decline, frailty and depressive symptoms. ${ }^{13}$ Their impact on quality of life, dependence and 
disability is considerable. The presence and number of geriatric syndromes are independently associated with a risk for adverse outcomes such as functional decline, the acquisition of additional syndromes, hospital admissions and mortality. ${ }^{14,15}$ Despite the contributing role of geriatric syndromes in the presentation, management and outcome of primary disease presentations, they are often under-recognized and seldom the focus of hospital and outpatient treatment. ${ }^{11}$ In addition, geriatric syndromes may also impact compliance and tolerance of common therapies utilized in the management of CVD (i.e. diuretics and antihypertensive therapy in the management of heart failure may precipitate worsening of falls and incontinence).

\section{- Frailty}

Frailty encompasses a biological decline across multiple interrelated organ systems and a subsequent loss of reserve in response to stressors, such as acute illness, and can result in a poor tolerance to CVD and/or to CVD therapy. Estimated prevalence of frailty in community dwelling older adults 65 and older is approximately $7 \%$ but increases to $20 \%$ in individuals over $80 .{ }^{16}$ In older patients hospitalized with CVD, especially heart failure, it is estimated that the prevalence is over $50 \% .{ }^{17}$ Frailty is an independent predictor of a wide range of CVD including subclinical CVD, ${ }^{18}$ coronary artery disease, congestive heart failure ${ }^{19}$ and CVD mortality ${ }^{20}$ and confers a $2-3$ increased risk of adverse events and mortality.

\section{Multimorbidity and CVD}

CVD affects approximately 40 million individuals in the US over the age of 65 and remains the leading cause of morbidity and mortality within that population both in the US and globally. ${ }^{2,4}$ Amongst Medicare beneficiaries with a diagnosis of CVD, the burden of multimorbidity is significant with over $50 \%$ of individuals that carry a diagnosis of heart failure or stroke also having 5 or more coexisting chronic medical conditions. ${ }^{8}$ Figure 3 shows the prevalence of coexisting chronic conditions in 6 of the most frequently managed diagnoses in cardiovascular medicine. It demonstrates the high prevalence $(>50 \%)$ of 3 or more additional chronic conditions with each diagnosis highlighting the complexity of managing CVD in older adults. ${ }^{8} 10$ For example, in older adults with ischemic heart disease, heart failure, stroke and atrial fibrillation the most common concomitant conditions are arthritis, anemia and diabetes mellitus and rates range from $40-50 \% .{ }^{10}$ Other common chronic conditions include chronic kidney disease, cognitive impairment, chronic obstructive lung disease and depression, each of which much be considered when developing individual treatment strategies for the management of CVD. In the case of coronary heart disease, common management strategies such as beta-blockade, anti-platelet therapy, antihypertensives and statin therapy ${ }^{21}$ may not be tolerated in an individual with chronic lung disease (25\%), anemia (39\%), dizziness and falls (35\%), and mobility difficulties (40\%). ${ }^{22}$ Table 1 highlights a few of the complexities and considerations managing an individual with systolic heart failure and a number of cardiac (hypertension, ischemic heart disease and atrial fibrillation), non-cardiac (chronic obstructive pulmonary disease, chronic kidney disease) coexisting conditions and a number of common geriatric syndromes (incontinence, falls and mobility impairment). 
Fundamental knowledge gaps in management of CVD in older adults in the context of multimorbidity lies in our reliance on evidence based guidelines derived from clinical trials that have largely recruited participants that are not proportionately representative of the majority of older patients managed by medical providers. Over half of clinical trials focused on the management of coronary artery disease failed to include any participant over the age of 75 years. ${ }^{23}$ Furthermore, individuals over the age of 75 make up less than $10 \%{ }^{23}$ of those included in any of the trials despite representing $25-32 \%$ of the population included in registries. ${ }^{24}$ Table 2 shows baseline patient characteristics of individuals from the Global Registry of Acute Coronary Events (GRACE) registry, a multinational, prospective registry that describes the epidemiology, management practices, and in-hospital outcomes and changes over time therein, of patients with the entire spectrum of acute coronary syndromes (ACSs). In comparison the corresponding baseline characteristic prevalence is shown for 3 ACS focused clinical trials (CAPTIM, ${ }^{25}$ CURE $^{26}$ and GUSTO IV ACS ${ }^{27}$ ). The comparison demonstrates that on average individuals in clinical trials are younger with a much smaller proportions $>65$, and $>75$, as compared to the ACS registry. They also have much lower prevalence of significant risk factors for adverse events such as the presence of heart failure, diabetes mellitus and prior stroke. In addition, there is no report and a low anticipated prevalence of significant risk factors such as falls, cognitive impairment, disability, and functional decline.

\section{Impact of multimorbidity and CVD}

While the incidence of multimorbidity in older adults increases, there remains very little data to inform clinicians on how to best care for older adults with multimorbidity and CVD. Advances in medical research and technology have evolved around the single-disease focused model resulting in significant reduction in morbidity and mortality from those specific disease processes (i.e. reduction in mortality following an acute myocardial infarction). However, in comparison very little attention has been devoted to coexisting and equally important multiple chronic conditions in a single patient. Figure 4 compares the traditional single disease focused conceptual framework with a more patient centered multimorbidity model. ${ }^{28}$ In the comorbid model approach, a single CVD diagnosis is the primary and index disease and all other conditions are viewed as secondary and less significant processes to be considered in the management. As a consequence, clinical practice guidelines focus mainly on treating the primary CVD and when comorbid conditions are considered, recommendations highlight pairs of disease processes such as atrial fibrillation and diabetes mellitus or heart failure and chronic kidney disease. Moreover, standard practice guidelines do not provide specific guidance to a provider managing an acute exacerbation of heart failure with acute on chronic kidney disease, poorly controlled diabetes mellitus, atrial fibrillation with recurrent falls and inadequate social support. The multimorbid conceptual framework demonstrates a more patient-centric approach to managing CVD in the context of multiple chronic conditions, geriatric syndromes, functional status and social determinants of health. In this framework, the presenting CVD represents the smallest component of managing the patient with increasing complexity with each layer of impacting factors. 
Older adults with multimorbidity are frequently seen by numerous general and specialist providers and utilize many services to manage individual diseases that may be inefficient, burdensome and duplicative. Increasing multimorbidity is associated with higher 30-day readmission rates. Despite contributing to only $14 \%$ of the Medicare population, individuals with 6 or more chronic conditions have 30-day hospital readmission rates $>25 \%$ and make up $70 \%$ of the population that is readmitted. Figure 5 shows the impact of multimorbidity on rates of readmissions in Medicare beneficiaries by increasing number of chronic conditions. ${ }^{8}$ Further, multimorbidity is also associated with much higher levels of per capita Medicare spending (Figure 5b) where individuals with 6 or more chronic conditions cost more than 3 times the average per capita spending. ${ }^{8}$

Poor care coordination and integration of care can also result in unsafe and competing management strategies by providers that may lead to multiple prescriptions for medications. Each provider will frequently adhere to standard of care clinical practice guidelines for individual chronic diseases which frequently leads to burdensome monitoring regimens and significant polypharmacy. ${ }^{29}$ As a consequence the patient becomes at risk for drug-drug interactions, drug-disease interactions and therapeutic competition (the recommended treatment for one condition may adversely affect and/or compete with another coexisting). ${ }^{30}$ Adverse consequences including poor adherence, adverse drug events, hospitalization and mortality are not only related to the number of medications but also to the regimen complexity. ${ }^{31,32}$ Studies have estimated that $50 \%$ of older adults are taking at least one medication with no ongoing indication, and many of these drugs are initiated during hospitalization, such as stress ulcer prophylaxis and antipsychotics for delirium. ${ }^{33}$

\section{Summary}

Multimorbidity is the most significant and common condition affecting older adults and impacts every component of health care management and delivery. The prevalence of multimorbidity significantly increases with age and is prevalent in over $70 \%$ of individuals 75 years or older. It represents the most common co-exisiting disease process in older adults and impacts the complexity of all aspects of disease management. For individuals with a diagnosis of CVD, multimorbidty has a significant effect on the presentation of the disease, the diagnosis, management and the patient-centered preferences in care. Conventional assessment of cardiovascular and therapeutic risk is based on extrapolation of guidelines developed from evidence demonstrated in younger individuals and fails to weight the increased burden of complications and multimorbidity. In addition, evidence based therapeutics have focused almost solely on cardiovascular focused morbidity (i.e. changes in ejection fraction, number of reperfusion events) and whilst excluding outcomes such as functional status, maintenance of independence and quality of life that may be of equal or more importance to an older adult. Over the next 25 years, the proportion of adults aged 65 and older is estimated to increase 3 fold, and with that remarkable change will come the complexities of managing this population. The resulting needs of these patients will require a fundamental shift in traditional care from single disease practices to a more patientcentered framework. 


\section{References}

1. Vincent, GK., Velkoff, VA. The next four decades: The older population in the United States: 2010 to 2050. US Department of Commerce, Economics and Statistics Administration, US Census Bureau; 2010. Available at: http://www.aoa.acl.gov/Aging_Statistics/future_growth/ future_growth.aspx

2. Roth GA, Forouzanfar MH, Moran AE, et al. Demographic and epidemiologic drivers of global cardiovascular mortality. New England Journal of Medicine. 2015; 372(14):1333-1341. Available at: http://www.ncbi.nlm.nih.gov/pubmed/25830423. [PubMed: 25830423]

3. Go AS, Mozaffarian D, Roger VL, et al. Heart disease and stroke statistics--2013 update: a report from the American Heart Association. Circulation. 2013; 127(1):e6. [PubMed: 23239837]

4. Mozaffarian D, Benjamin EJ, Go AS, et al. Heart disease and stroke statistics-2015 update: a report from the american heart association. Circulation. 2015; 131(4):e29. Available at: http:// www.ncbi.nlm.nih.gov/pubmed/25520374. [PubMed: 25520374]

5. Boyd CM, Vollenweider D, Puhan MA. Informing evidence-based decision-making for patients with comorbidity: availability of necessary information in clinical trials for chronic diseases. PloS one. 2012; 7(8):e41601. Available at: http://www.ncbi.nlm.nih.gov/pubmed/22870234. [PubMed: 22870234]

6. Fihn SD, Gardin JM, Abrams J, et al. 2012 ACCF/AHA/ACP/AATS/PCNA/SCAI/STS guideline for the diagnosis and management of patients with stable ischemic heart disease: a report of the American College of Cardiology Foundation/American Heart Association task force on practice guidelines, and the American College of Physicians, American Association for Thoracic Surgery, Preventive Cardiovascular Nurses Association, Society for Cardiovascular Angiography and Interventions, and Society of Thoracic Surgeons. Journal of the American College of Cardiology. 2012; 60(24):e44-e164. [PubMed: 23182125]

7. Tinetti ME, Fried TR, Boyd CM. Designing health care for the most common chronic conditionmultimorbidity. Jama. 2012; 307(23):2493-2494. [PubMed: 22797447]

8. Centers for Medicare \& Medicaid Services. [Accessed on: November 25th, 2015] Chronic Conditions Overview. Available at: https://www.cms.gov/Research-Statistics-Data-and-Systems/ Statistics-Trends-and-Reports/Chronic-Conditions/CC_Main.html

9. Rocca, WA., Boyd, CM., Grossardt, BR., et al. Prevalence of multimorbidity in a geographically defined American population: patterns by age, sex, and race/ethnicity. Paper presented at: Mayo Clinic Proceedings; 2014. Available at: http://www.ncbi.nlm.nih.gov/pubmed/25220409

10. Arnett DK, Goodman RA, Halperin JL, Anderson JL, Parekh AK, Zoghbi WA. AHA/ACC/HHS strategies to enhance application of clinical practice guidelines in patients with cardiovascular disease and comorbid conditions: from the American Heart Association, American College of Cardiology, and US Department of Health and Human Services. Journal of the American College of Cardiology. 2014; 64(17):1851-1856. Available at: http://www.ncbi.nlm.nih.gov/pubmed/ 25212466. [PubMed: 25219921]

11. Inouye SK, Studenski S, Tinetti ME, Kuchel GA. Geriatric syndromes: clinical, research, and policy implications of a core geriatric concept. Journal of the American Geriatrics Society. 2007; 55(5):780-791. [PubMed: 17493201]

12. Tinetti ME, Inouye SK, Gill TM, Doucette JT. Shared risk factors for falls, incontinence, and functional dependence: unifying the approach to geriatric syndromes. Jama. 1995; 273(17):13481353. [PubMed: 7715059]

13. Lee PG, Cigolle C, Blaum C. The Co-Occurrence of Chronic Diseases and Geriatric Syndromes: The Health and Retirement Study. Journal of the American Geriatrics Society. 2009; 57(3):511516. [PubMed: 19187416]

14. Buurman BM, Hoogerduijn JG, de Haan RJ, et al. Geriatric conditions in acutely hospitalized older patients: prevalence and one-year survival and functional decline. PloS one. 2011; 6(11):e26951. [PubMed: 22110598]

15. Anpalahan M, Gibson S. Geriatric syndromes as predictors of adverse outcomes of hospitalization. Internal medicine journal. 2008; 38(1):16-23. [PubMed: 17542997] 
16. Fried LP, Tangen CM, Walston J, et al. Frailty in older adults: evidence for a phenotype. J Gerontol A Biol Sci Med Sci. 2001; 56(3):M146-156. Available at: http://www.ncbi.nlm.nih.gov/pubmed/ 11253156. [PubMed: 11253156]

17. Afilalo J, Karunananthan S, Eisenberg MJ, Alexander KP, Bergman H. Role of frailty in patients with cardiovascular disease. Am J Cardiol. 2009; 103(11):1616-1621. [PubMed: 19463525]

18. Newman AB, Gottdiener JS, McBurnie MA, et al. Associations of subclinical cardiovascular disease with frailty. J Gerontol A Biol Sci Med Sci. 2001; 56(3):M158-166. [PubMed: 11253157]

19. Cacciatore F, Abete P, Mazzella F, et al. Frailty predicts long-term mortality in elderly subjects with chronic heart failure. Eur J Clin Invest. 2005; 35(12):723-730. [PubMed: 16313247]

20. Ekerstad N, Swahn E, Janzon M, et al. Frailty is independently associated with short-term outcomes for elderly patients with non-ST-segment elevation myocardial infarction. Circulation. 2011; 124(22):2397-2404. [PubMed: 22064593]

21. Williams MA, Fleg JL, Ades PA, et al. Secondary prevention of coronary heart disease in the elderly (with emphasis on patients $>$ or $=75$ years of age): an American Heart Association scientific statement from the Council on Clinical Cardiology Subcommittee on Exercise, Cardiac Rehabilitation, and Prevention. Circulation. 2002; 105:1735-43. [PubMed: 11940556]

22. Boyd CM, Leff B, Wolff JL, et al. Informing clinical practice guideline development and implementation: prevalence of coexisting conditions among adults with coronary heart disease. Journal of the American Geriatrics Society. 2011; 59(5):797-805. Available at: http:// www.ncbi.nlm.nih.gov/pubmed/21568950. [PubMed: 21568950]

23. Lee PY, Alexander KP, Hammill BG, Pasquali SK, Peterson ED. Representation of elderly persons and women in published randomized trials of acute coronary syndromes. JAMA. 2001; 286(6): 708-713. [PubMed: 11495621]

24. Steg PG, Goldberg RJ, Gore JM, et al. Baseline characteristics, management practices, and inhospital outcomes of patients hospitalized with acute coronary syndromes in the Global Registry of Acute Coronary Events (GRACE). Am J Cardiol. 2002; 90(4):358-363. [PubMed: 12161222]

25. Bonnefoy E, Lapostolle F, Leizorovicz A, et al. Primary angioplasty versus prehospital fibrinolysis in acute myocardial infarction: a randomised study. The Lancet. 2002; 360(9336):825-829.

26. Yusuf S, Zhao F, Mehta SR, et al. Effects of clopidogrel in addition to aspirin in patients with acute coronary syndromes without ST-segment elevation. N Engl J Med. 2001; 345(7):494-502. [PubMed: 11519503]

27. Effect of glycoprotein IIb/IIIa receptor blocker abciximab on outcome in patients with acute coronary syndromes without early coronary revascularisation: the GUSTO IV-ACS randomised trial. The Lancet. 2001; 357(9272):1915-1924.

28. Boyd CM, Fortin M. Future of multimorbidity research: how should understanding of multimorbidity inform health system design. Public Health Rev. 2010; 32(2):451-474.

29. Boyd CM, Darer J, Boult C, Fried LP, Boult L, Wu AW. Clinical practice guidelines and quality of care for older patients with multiple comorbid diseases: implications for pay for performance. Jama. 2005; 294(6):716-724. Available at:http:/www.ncbi.nlm.nih.gov/pubmed/16091574. [PubMed: 16091574]

30. Lorgunpai SJ, Grammas M, Lee D, McAvay G, Charpentier P, Tinetti ME. Potential therapeutic competition in community-living older adults in the US: use of medications that may adversely affect a coexisting condition. PloS one. 2014; 9(2):e89447. [PubMed: 24586786]

31. Lau DT, Kasper JD, Potter D, Lyles A, Bennett RG. Hospitalization and death associated with potentially inappropriate medication prescriptions among elderly nursing home residents. Archives of internal medicine. 2005; 165(1):68-74. [PubMed: 15642877]

32. Claxton AJ, Cramer J, Pierce C. A systematic review of the associations between dose regimens and medication compliance. Clinical therapeutics. 2001; 23(8):1296-1310. [PubMed: 11558866]

33. Morandi A, Vasilevskis E, Pandharipande PP, et al. Inappropriate medication prescriptions in elderly adults surviving an intensive care unit hospitalization. Journal of the American Geriatrics Society. 2013; 61(7):1128-1134. [PubMed: 23855843]

34. Palmer MH, Hardin SR, Behrend C, Collins SK-R, Madigan CK, Carlson JR. Urinary incontinence and overactive bladder in patients with heart failure. The Journal of urology. 2009; 182(1):196202. [PubMed: 19447424] 
35. Wong CY, Chaudhry SI, Desai MM, Krumholz HM. Trends in comorbidity, disability, and polypharmacy in heart failure. The American journal of medicine. 2011; 124(2):136-143. [PubMed: 21295193]

36. Stenhagen M, Ekström H, Nordell E, Elmståhl S. Falls in the general elderly population: a 3-and 6year prospective study of risk factors using data from the longitudinal population study 'Good ageing in Skane'. BMC geriatrics. 2013; 13(1):81. [PubMed: 23919320]

37. Pocock SJ, McMurray JJ, Dobson J, et al. Weight loss and mortality risk in patients with chronic heart failure in the candesartan in heart failure: assessment of reduction in mortality and morbidity (CHARM) programme. European heart journal. 2008; 29(21):2641-2650. [PubMed: 18819960] 


\section{Key Points}

- Multimorbidity, the presence of 2 or more chronic conditions, is the most common disease process impacting older adults

- The prevalence of multimorbidity increases with age such that it is prevalent in $>70 \%$ of adults aged 75 years and older

- Assessment of multimorbidity should also include presence of geriatric syndromes

- Multimorbidity is common in the presence of CVD especially heart failure where $50 \%$ of Medicare beneficiaries have 5 or more coexisting chronic conditions

- Multimorbidity has a substantial impact on disease management, quality of life, health care costs and health care utilization. 


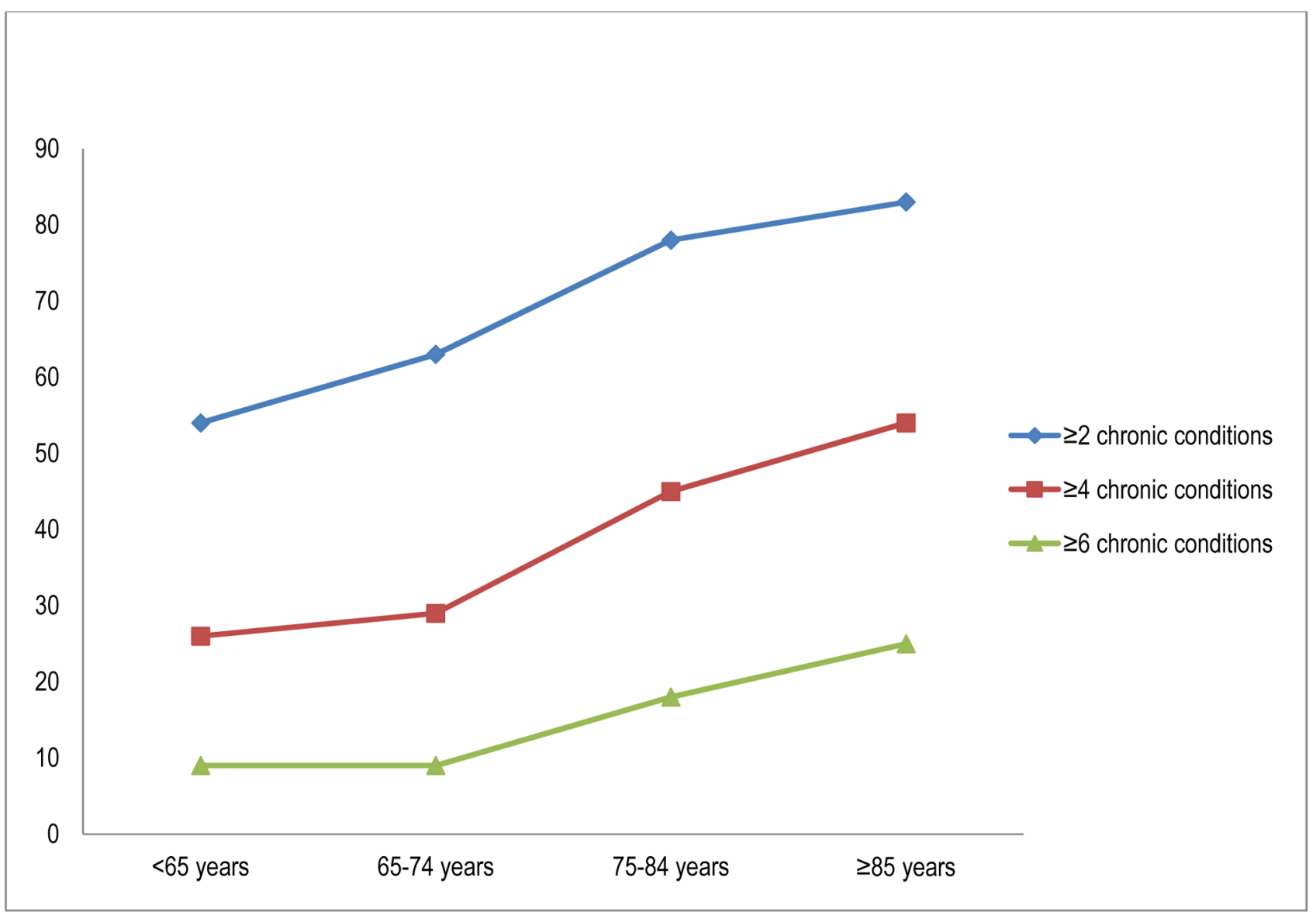

Figure 1.

Percentage of Medicare Fee-for Service Beneficaries by Number of Multiple Chronic Conditions and Age (2010) showing increasing prevalence of multimorbidity with increasing age 


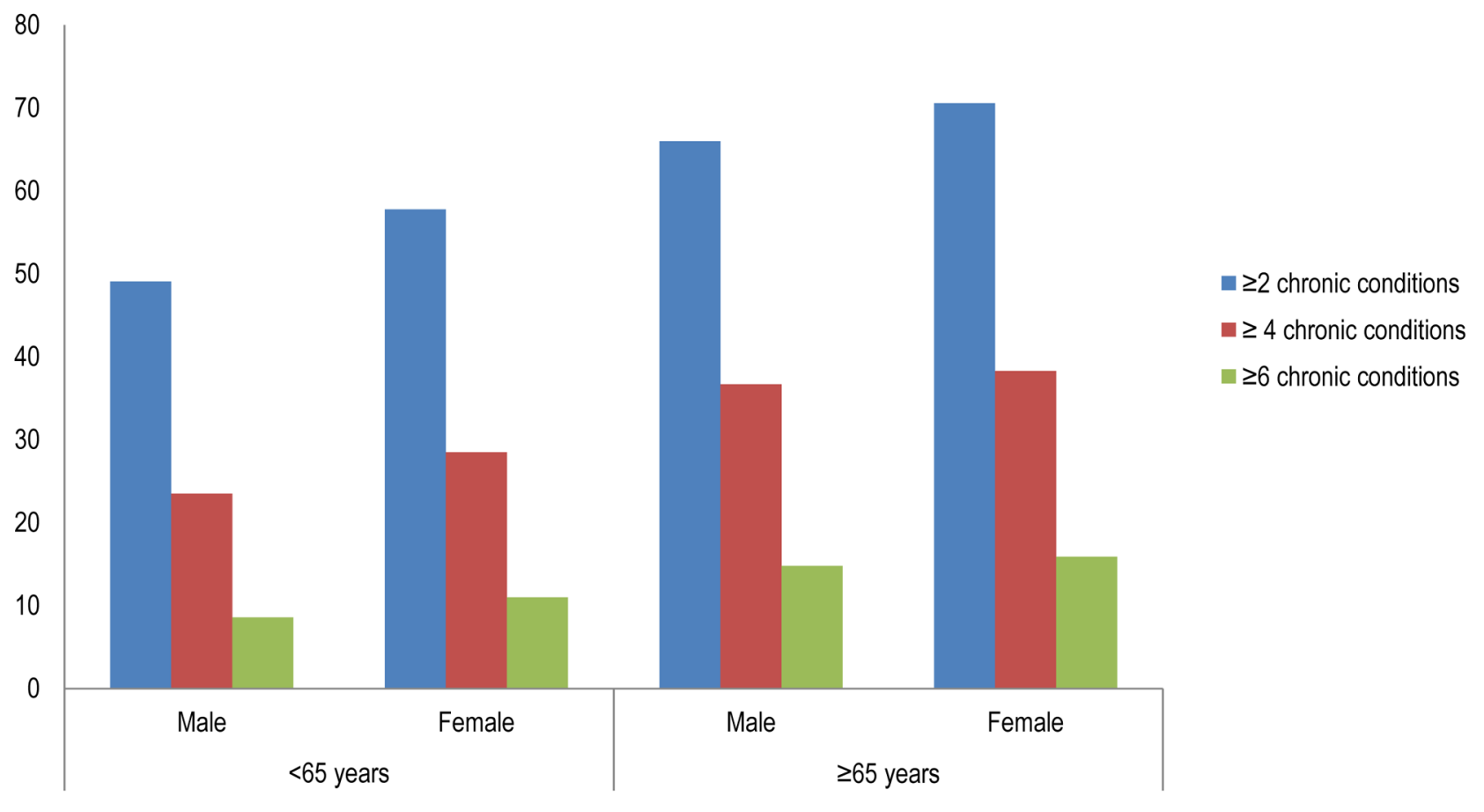

Figure 2.

Age and sex associated prevalence of multimorbidity by number of chronic conditions demonstrating the higher prevalence of number of chronic conditions above 65 as compared to below 65 and the higher prevalence of multimorbidity in women as compared to men. 


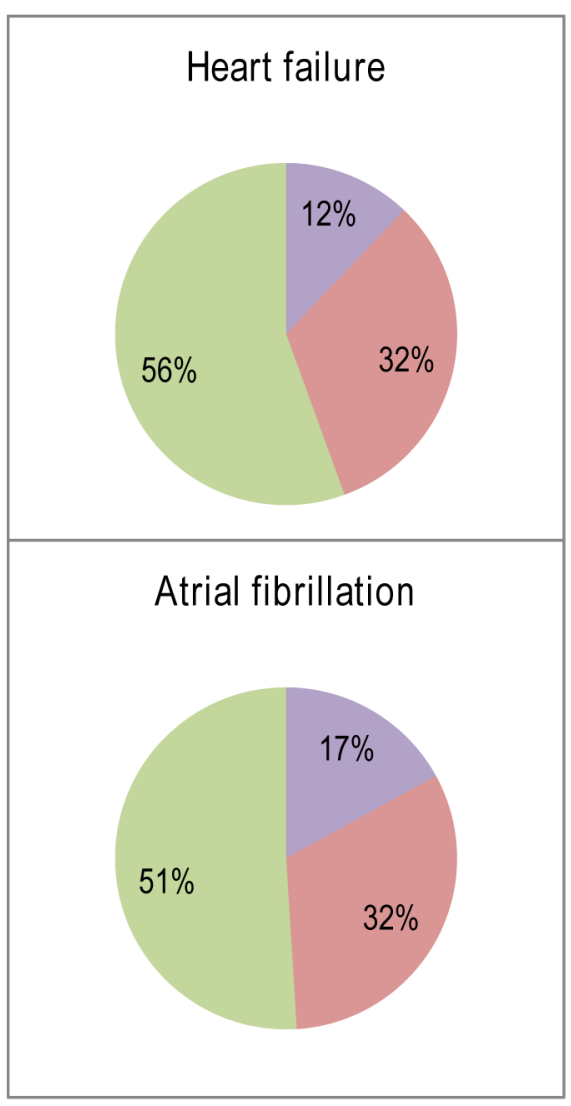

$\leq 2$ other chronic conditions
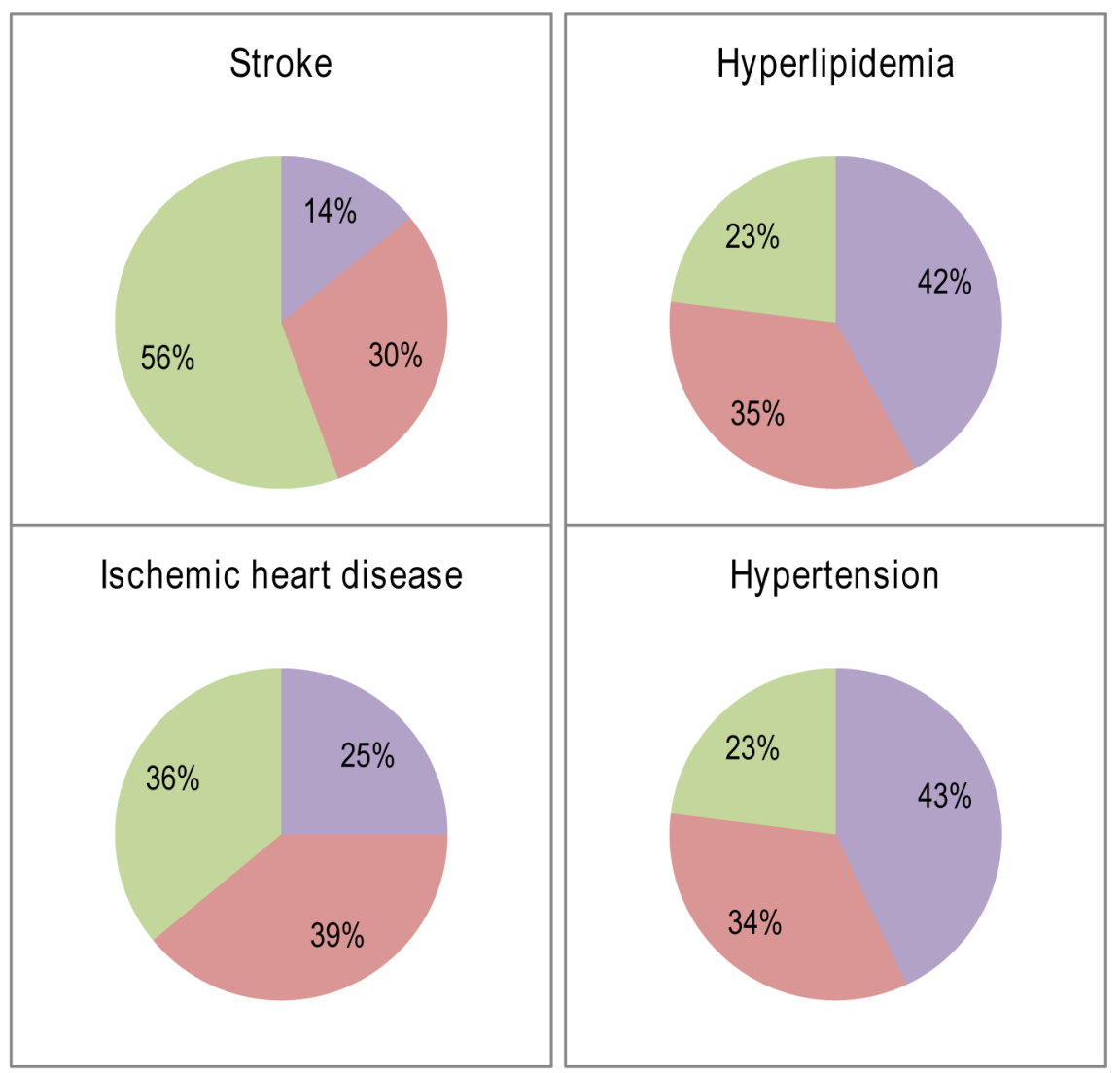

3-4 other chronic conditions $\geq 5$ other chronic conditions

Figure 3.

Number of co-existing chronic conditions amongst Medicare Fee for Service Beneficiaries with common cardiovascular diagnoses 


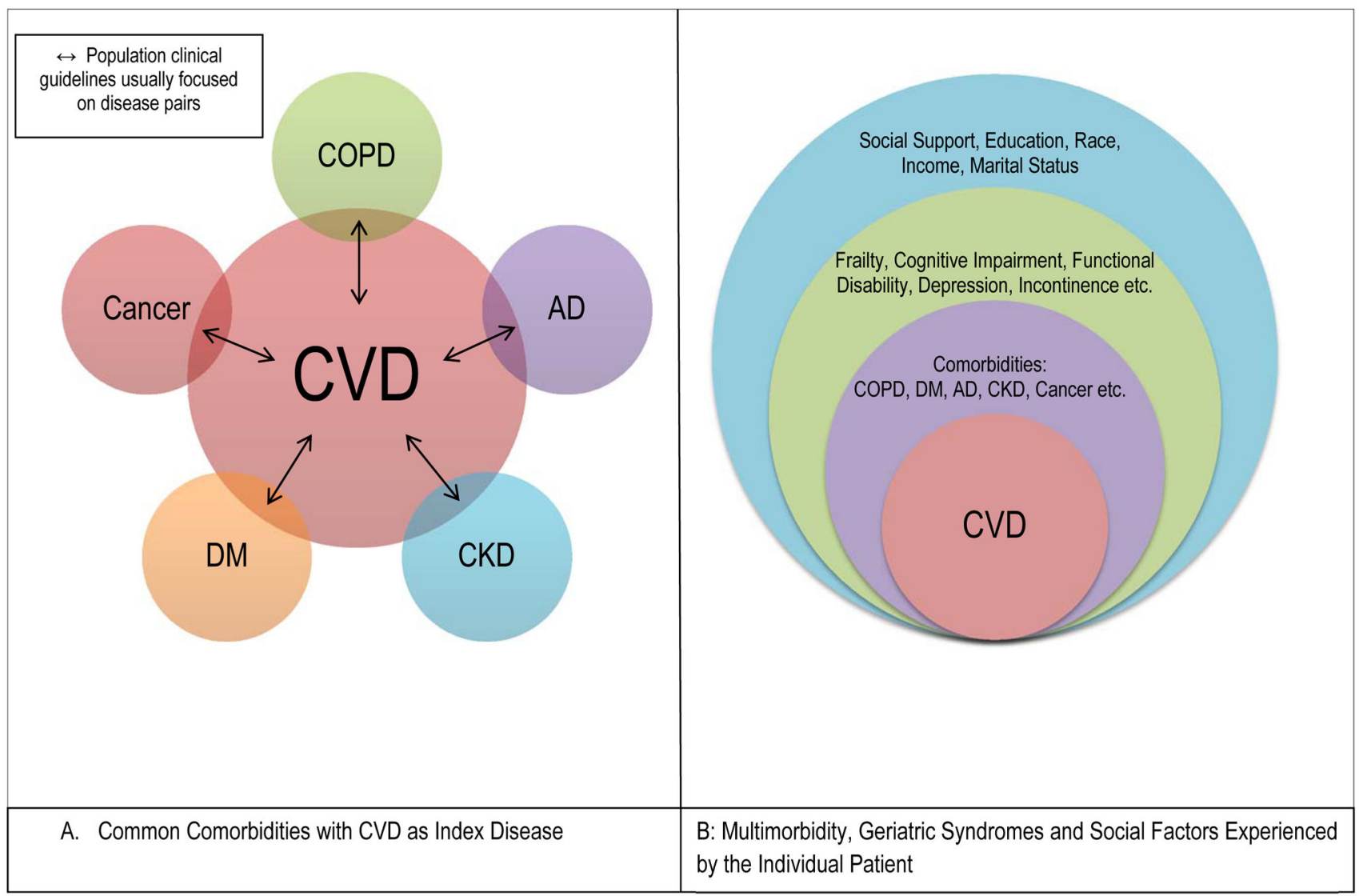

Figure 4.

Conceptual model of comorbidity vs. multimorbidity in the context of CVD. A: Comorbid conceptual framework demonstrating the traditional disease-centered approach to understanding disease processes. Clinical practice guidelines are based on this framework where at most when comorbid conditions are considered they focus on disease pairs, such as CVD and diabetes mellitus or CVD and chronic kidney disease. B: Multimorbid conceptual framework demonstrating a more patient-centric approach to managing CVD in the context of multiple chronic conditions, geriatric syndromes, functional status and social determinants of health. 


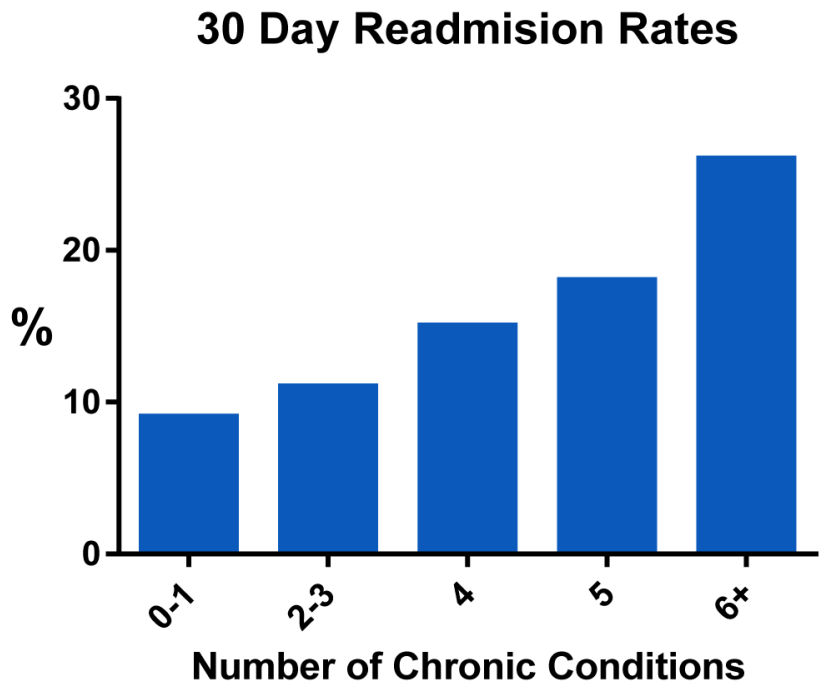

A.

\section{Per Capita Medicare Spending by Number of Chronic Conidtions}

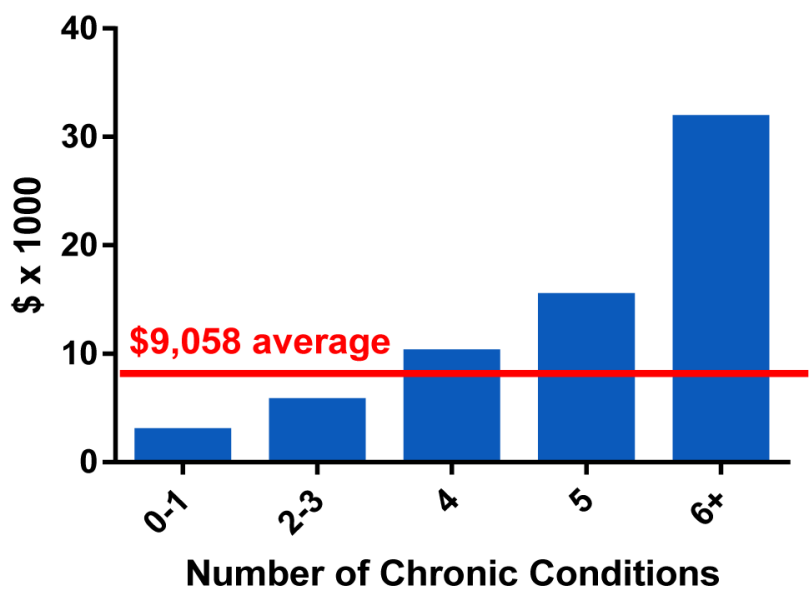

B.

Figure 5.

A: Readmission rates for Fee-for-Service Medicare beneficiaries by number of chronic conditions showing that readmission rates increase with increasing number of chronic conditions. B: Per Capita spending for Medicare beneficiaries by number of chronic conditions showing that individuals with 6 or more chronic conditions cost over 3 times the average spending rate. 


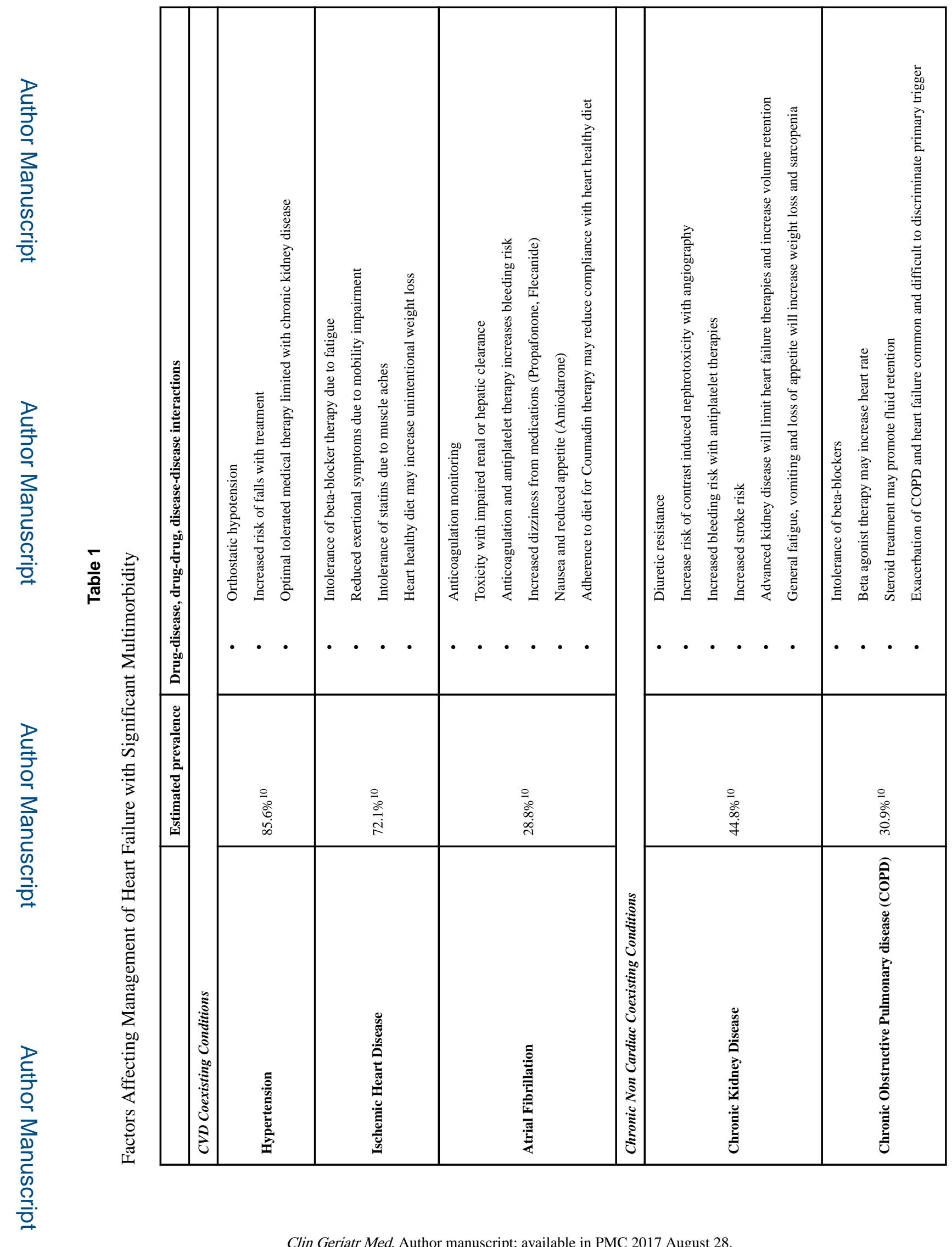




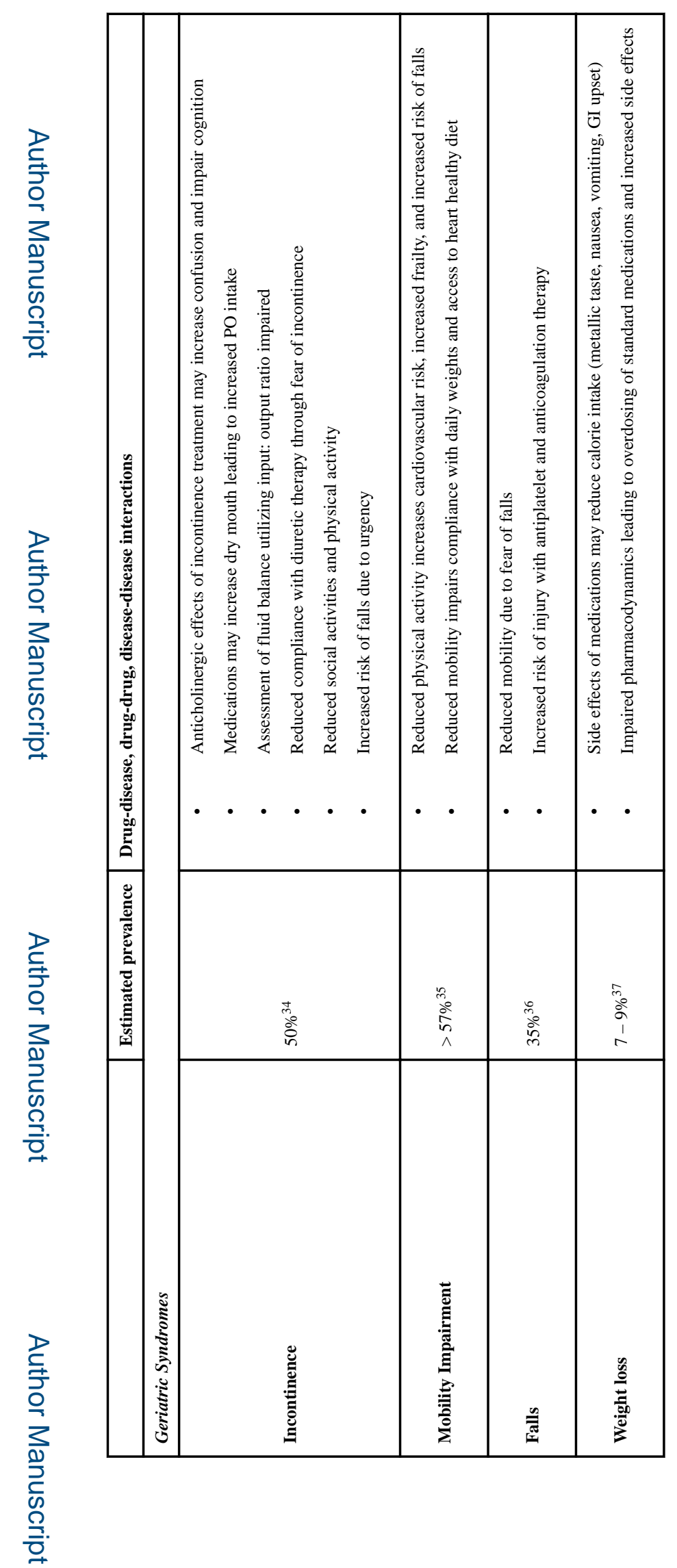

Clin Geriatr Med. Author manuscript; available in PMC 2017 August 28. 


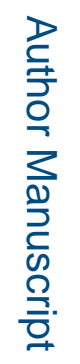

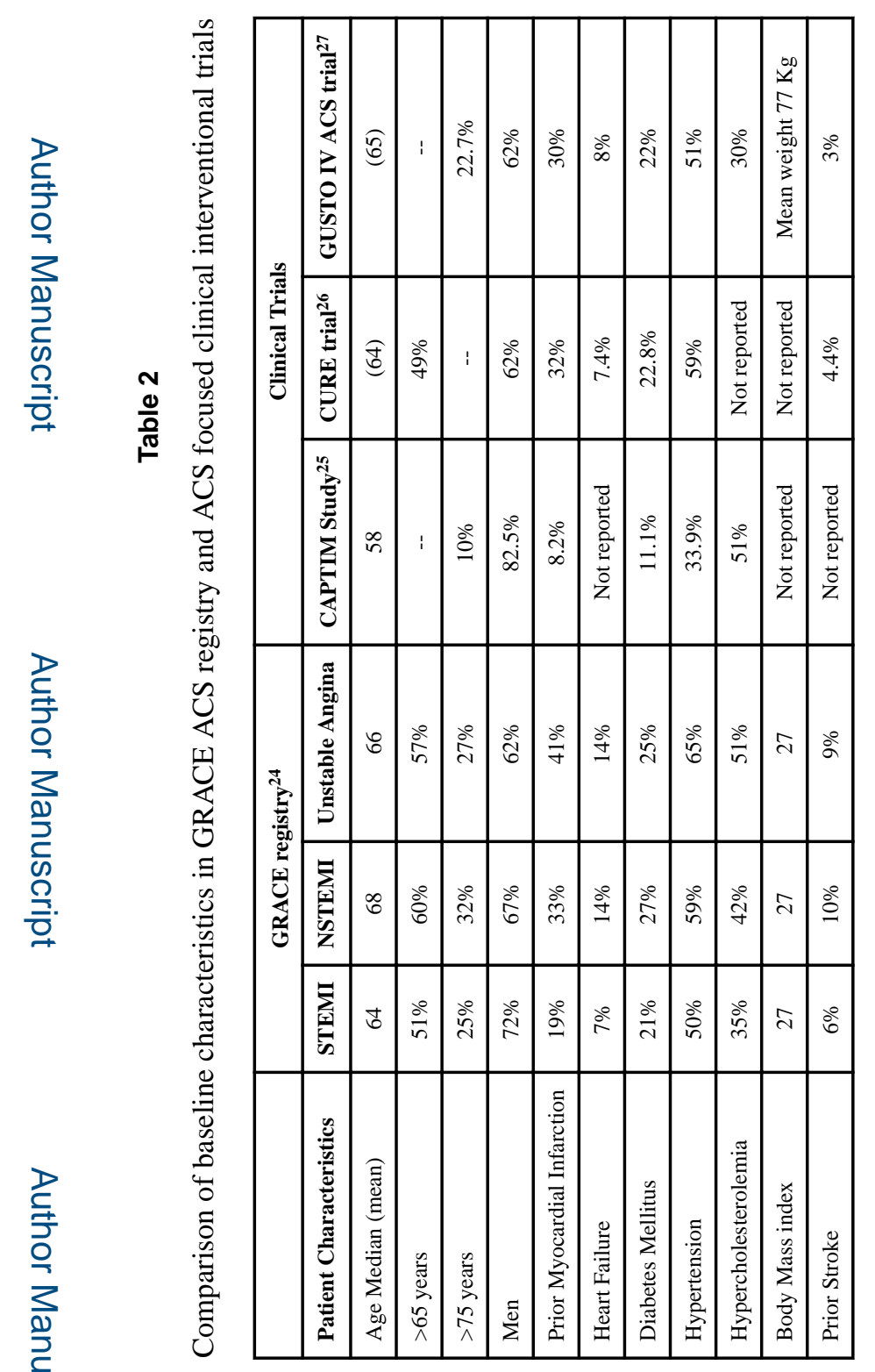

Clin Geriatr Med. Author manuscript; available in PMC 2017 August 28. 